\title{
A Novel Gaussian Particle Swarms optimized Particle Filter Algorithm for the State of Charge Estimation of Lithium-ion Batteries
}

\author{
Xinyang Wang ${ }^{1}$, Shunli Wang, ${ }^{1, *}$, Junhan Huang ${ }^{1}$, Carlos Fernandez ${ }^{2}$, Yicong Zhou ${ }^{1}$, Lei Chen ${ }^{1}$ \\ ${ }^{1}$ School of Information Engineering, Southwest University of Science and Technology, Mianyang \\ 621010, China; \\ ${ }^{2}$ School of Pharmacy and Life Sciences, Robert Gordon University, Aberdeen AB10-7GJ, UK. \\ *E-mail: $497420789 @$ qq.com
}

doi: $1020964 / 2020.10 .21$

Received: 1 June 2020 / Accepted: 17 Jul 2020 / Published: 31 August 2020

\begin{abstract}
A gaussian particle swarm optimized particle filter estimation method, along with the second-order resistance-capacitance model, is proposed for the state of charge estimation of lithium-ion battery in electric vehicles. Based on the particle filter method, it exploits the strong optimality-seeking ability of the particle swarm algorithm, suppressing algorithm degradation and particle impoverishment by improving the importance distribution. This method also introduces normally distributed decay inertia weights to enhance the global search capability of the particle swarm optimization algorithm, which improves the convergence of this estimation method. As can be known from the experimental results that the proposed method has stronger robustness and higher filter efficiency with the estimation error steadily maintained within $0.89 \%$ in the constant current discharge experiment. This method is insensitive to the initial amount and distribution of particles, achieving adaptive and stable tracking in the state of charge for lithium-ion batteries.
\end{abstract}

Keywords: Lithium-ion Battery; State of Charge; Particle Filter; Particle Swarm Optimization; Importance Resampling

\section{FULL TEXT}

(C) 2020 The Authors. Published by ESG (www.electrochemsci.org). This article is an open access article distributed under the terms and conditions of the Creative Commons Attribution license (http://creativecommons.org/licenses/by/4.0/). 